\title{
Theorizing a Social Repair Orientation to Disaster Recovery: Developing Insights for Disaster Recovery Policy and Programming
}

\author{
Omer Aijazi
}

Published online: 15 May 2014

(C) Springer International Publishing 2014

\begin{abstract}
This paper conceptualizes a social repair orientation to disaster recovery for policy makers and programmers. It locates the concept of social repair in a variety of academic disciplines and identifies two distinct understandings of social repair: resumption of everyday life and re-humanization/reconstituting the self. The paper then theorizes the agency of memory, hope and resistance as strategic tools for achieving social repair. Additionally, social learning is used to describe the use of these tools by disaster survivors to achieve social repair. Finally, the paper delineates the differences between a social repair orientation to disaster recovery and existing disaster recovery praxis, offering guidance for policy makers and programmers.
\end{abstract}

Keywords Social repair - Disaster recovery - Everyday life · Social learning $\cdot$ Resistance $\cdot$ Memory

\section{Introduction}

Natural disasters can easily be conceptualized as forms of collective violence, which disrupt the lives of large numbers of people and are intensified by prevailing political, social and economic conditions. Like mass violence, disasters too can erode "societal structures, social and economic institutions, and networks of familial and intimate relationships that provide the foundations of a functional community" (Fletcher and Weinstein 2002, p. 576). Similar to experiences of violence, natural disasters force survivors to confront questions about their continued place in the world, desired ways to inhabit it and work towards a life of meaning. However, these processes

O. Aijazi $(\bowtie)$

Department of Educational Studies, Liu Institute for Global Issues, University of British Columbia, Vancouver, BC, Canada

e-mail: omer.aijazi@utoronto.ca of working towards a life of meaning remain unnamed and unexplored within existing scholarship on natural disasters.

This paper takes its point of departure from existing disaster recovery praxis. It proposes a social repair orientation to disaster recovery, as it relates to intimate processes of social remaking that communities and individuals engage in as they move from a space of social disruption (such as after natural disasters) towards a life of meaning. A social repair orientation makes its conceptual break from the diminishing notion of survival which characterizes existing disaster recovery praxis and invests in a more holistic understanding of life after disasters.

This paper conceptualizes a social repair orientation to disaster recovery for policy makers and programmers. It locates the concept of social repair in a variety of academic disciplines and identifies two distinct understandings of social repair: resumption of everyday life and re-humanization/reconstituting the self. The paper then theorizes the agency of memory, hope and resistance as strategic tools for achieving social repair. Additionally, social learning is used to describe the use of these tools by disaster survivors to achieve social repair. Finally, the paper delineates the differences between a social repair orientation to disaster recovery and existing disaster recovery praxis, offering guidance for policy makers and programmers. Essentially, the paper responds to the following questions: What are some existing approaches to social repair? What kinds of tools do people use to accomplish these processes of social repair? How can these approaches to social repair inform disaster recovery policy and programming?

The choice of literature used is broad. These include selective works from the anthropology of violence, critical adult education and social learning in struggle, North American indigenous writings on resistance, interdisciplinary political science, sociological literature on disasters, applied anthropology and other places which grapple with the liquid concept of 
social repair and remaking after disruption. This wide array of literature reflects the complex nature of human experiences of disruption, necessitating a multimodal and multidisciplinary re-reading of the world. The paper also makes a case for interdisciplinarity, and encourages readers to look in the "cracks between our categories and in the discursive processes that traverse our disciplines" (Kleinman et al. 1996, p. xiii).

\section{Towards an Orientation of Social Repair After Natural Disasters: Some Existing Imaginaries}

Two important conceptualizations of social repair inform this paper. These are the conceptual notions of re-humanization/reconstituting the self as developed by Freire (1970) and resumption of everyday life as envisioned by Das (2007). Interestingly, neither of these works is situated within the context of natural disasters, indicating a lack of research on the embodied experiences of disasters and ensuing struggles for recovery. Freire's (1970) work arises from his experiences with popular education initiatives in rural Brazil and elsewhere, whereas Das (2007) writes on communal violence in India. Their works vary in their intensity of "ethnographic refusal" (Ortner 1995), but such a discussion is beyond the scope of this paper.

\section{(Re-) Becoming Human/Re-Constituting the Self}

At the heart of Freire's (1970) book Pedagogy of the Oppressed rests the central question: What does it mean to be human? This has two important dimensions: firstly, how do external interventionists conceptualize the intervened; what attributes of humanity do they prescribe to them? Secondly, how do the oppressed see themselves in relation to their world, what qualities of humanity do they attribute to themselves?

Freire (1970) regards human beings as inherently agentive though constrained and de-humanized by structural systems of oppression. However, Freire argues that "dehumanization is not a given destiny" (p. 26) and can be rectified. Freire's vision of social repair is rooted in this process of rehumanization, or re-constituting the self. Central to this vision is regaining confidence in one's knowledge systems and cultural tools for sense making (p.45). He distinguishes between objective reality (e.g. the lack of material provisions, such a food) and subjective reality, which alludes to how people engage in sense making and interpret/understand the conditions of their oppression. His vision of humanization involves transformation in both frames of reality.

Freire (1970) regards freedom as being an essential component of his vision of human completion, referring to the capacity to have agency and engage in the "ontological and historical vocation of becoming more fully human" (p. 48). Rooted in a distinctively Marxist worldview, the capacity for action embedded in Freire's vision refers to larger processes of revolutionary change. However, it is important to point out that even this revolutionary logic depends on micro-processes of consciousness building that is developed during the unfolding of daily life. Even though Freire specifies learning and pedagogical spaces to include class rooms and study circles, these spaces can be extended to include the less structured domains of everyday life. Using Freire's logic, everyday life, experiences of oppression and struggle themselves constitute as learning/pedagogical spaces and this is reflected in the theoretical impetus of conceptualizing the everyday as a valid scale of inquiry.

Re-humanization or re-constituting the self is the process by which subjects rediscover their agency and historicity. For example, these conceptual offerings have been taken up by Chaudhry (2004) in her exploration of how ethnic women remade themselves after violence in Karachi, Pakistan. Using life history interviews of two such women, Chaudhry (2004) reveals that for these women an act of remaking meant constituting/establishing themselves as agents (i.e. possessing agency) despite overwhelming structural constraints in their immediate lives. Similarly, Donnan and Simpson's (2007) exploration of stories of violence along the Irish border in the 1970s and 1980s revealed that subjects strove to rediscover their agency and historicity by breaking the silence that surrounded their experiences of violence. Rosenoff-Gauvin's (2013) ethnographic research in post-conflict Uganda explores the processes of intergenerational knowledge transmission which enabled survivors to make meaning in the world, re-establish historicity and form a moral community. Freire's (1970) analysis leads us to believe that perhaps after a natural disaster the first thing a survivor needs is to be recognized and acknowledged as a human being. Such an acknowledgement of being human entails recognition of the will to continue on living. As if the survivor would say "I was a real person, a historical being, with hopes and aspirations, I still am—now I will beat this and I will persevere."

\section{Resumption of Every Day Life}

Das's (2007) nuanced engagement with survivors of communal violence draws attention to the delicate acts of self-creation embedded in the process of re-occupying the same spaces of daily life where one once experienced disruption. She writes "I found that making of the self was located not in the shadow of some ghostly past, but in the context of making the everyday inhabitable" (p. 216). Thus, the very act of picking up pieces and resuming life in the very same spaces of devastation is in itself an act of social repair. She asserts:

My own engagement with the survivors of riots also showed me that life was recovered not through some grand gestures in the realm of the transcendent but 
through a descent into the ordinary. There was I argue, a mutual a absorption of the violent and the ordinary so that I end up thinking of the event as always attached to the ordinary as if they were tentacles that reach out from the everyday and anchor the event to it in some specific way. (p. 7)

The re-occupation of everyday life is concerned with the creation of the subject. Like Freire (1970), Das (2007) too is interested in revealing the agency of disrupted individuals and focuses on shifts in their subjective realities as a means of sense making, embracing injuries and redeeming life. Das concentrates on the betrayal of everyday life. She argues that it is the space of daily life where violence is enacted and experienced, and where one also "ceases to trust the context in place" (p.9). Recovering the everyday is essentially "coming to terms with the fragility of the normal" (Mehta and Chatterji 2001, p. 202), and dismantling the "feelings of skepticism embedded within a frayed everyday life" (Das 2007 , p. 9) which the previously protective guarantees of community or state can no longer erase. This also involves establishing a narrative continuity by connecting one's present with the past (Das, p. 73). For example, Chamlee-Wright (2010) describes how communities displaced from New Orleans by Hurricane Katarina articulated missing familiar foods such as pickled pork and chicory coffee which disrupted their efforts at restarting their lives elsewhere (p.116). Similarly, women in post-flood Pakistan recalled making chappatis (flat bread) just as they did in their kitchens before the flood for men who worked on rebuilding each other's homes (Aijazi, O., and Panjwani, D., Religion as counter-narrative and capacity for action in spaces of social disruption: a rereading of the public transcript and disaster relief in postflood Pakistan, International Journal of Mass Emergencies and Disasters, forthcoming). For these women, the act of making chappatis constituted a return to the everyday. de Alwis (2004) shows how Muslim women reoccupied everyday life in refugee camps and these could potentially "reconfigure and transform the present as well as the future of lived reality within the context of displacement" (p. 227). Baines and RosenoffGauvin (2014) also make a case for the descent into the everyday as a form of social repair by exploring the stories of two women who struggled to overcome their displacement from family networks by taking on culturally mediated notions of motherhood in other communal ways.

\section{Tools for Social Repair: Memory, Hope and Resistance}

After getting a glimpse of the aesthetics of social repair, the paper focuses its attention to the actual strategies available to socially disrupted populations for embarking on their personal and collective journeys of remaking. This paper focuses on three such socially embedded capabilities: memory, hope and everyday acts of resistance. These are discussed as possible mechanisms of achieving social repair and remaking as reflected in the narratives of re-humanization/re-constituting the self and resumption of daily life.

\section{Acts of Remembering; Embodied Memories}

The act of remembering as a weaving together of narratives for sense-making, one that links the present with the past, before the disruption to after, is an important strategy for social repair and remaking. One way in which memory becomes a strategy for social repair is in its articulation as attachment to place. Memory like culture sits in place, in objects, in socially constructed rituals and in daily life routines.

Embedded within objects and spaces are sets of "relationships that link people to each other, to their environment and to their way of life" (Oliver-Smith 2010, p. 178). They serve as grounding for historical continuity and "acquires multiple meanings, expressive of physical, emotional and experiential realities" (Oliver-Smith, p. 165). If dislocated, people must struggle to "construct a life world that can clearly articulate their continuity and identity as people again" (Oliver-Smith, p. 167), and therefore forced "resettlement not only relocates a people in space, but remakes them" (Oliver-Smith, p. 170). Place also mediates as a space through which people are linked together via long rooted and shared histories, tying generations together in a "community of memory" (Oliver-Smith, p. 183). It is through such communities of memory that people come to know themselves "as members of a people, as inheritors of a history and a culture that we must nurture through memory and hope" (Bellah et al. 1985, p. 138 as quoted in Oliver-Smith 2010, p. 183).

It is possible to reconstruct places/spaces/meaningful objects and re-embed with them with memories (old and new) in a process of re-anchoring. In fact, it has been suggested that the process of recovery is encoded in this reconstruction and repossession of objects and spaces of cultural significance such as schools, playgrounds, places of worship (Chamlee-Wright 2010; Riaño-Alcalá 2006; Riaño-Alcalá, P., Emplaced witnessing: commemorative practices among the Wayuu in the Upper Guajira, Memory Studies, forthcoming). RiañoAlcalá explores the notion of emplaced witnessing in commemorative practices of indigenous communities in Colombia in the context of a massacre and forced displacement. Communities return to the original site of disruption annually and re-enact everyday life before disruption. In these acts of commemoration, everyday life is temporarily reconstructed as a site of social meaning and truth telling (Riaño-Alcalá, forthcoming). This enactment and temporary construction of place is used to make territorial claims and "transform local pains and memories into meaningful acts of community reconstruction and draw from these implications matters of truth telling, justice and repair in larger socio-political contexts" (Riaño-Alcalá, forthcoming). 
Memory is reclaimed and recreated after disruption in an effort to establish some form of historical continuity and maintain relationships between oneself and others. This does not refer to a simple recollection of events, but a subjective re-rendering and work is actually performed. One function of memory is to create meaning. "Meaning can be imposed on suffering if it serves some purpose and if that purpose and the experience of suffering are recognized as significant by others" (Oliver-Smith 2010, p. 179). It is challenging for the disrupted to create a sense of meaning for their loss and experiences of rupture and to "integrate it into some context consistent with the values and beliefs of their culturebridging time before and time after" (Oliver-Smith, p. 179). Das (2007) gives an example of abducted women after the IndiaPakistan Partition who now married and living with their new husbands felt that "the obligation to maintain a narrative continuity with the past contradicted the ability to live in the present" (p.29). Since their current husbands were the very men who killed their original husbands and fathers. Shaw (2002) encourages us to focus on the "creative forms of coherence" subjects weave across their experiences of disruption, which are essentially forms of reconfiguring and remembering disruption (p. 22). People use memory to effectively develop ways of remembering themselves as moral communities and maintaining through discursive memory a sense of ancestral continuity (p. 69).

The ability to forge memories and forgetfulness in new ways (Das and Kleinman 2001, p. 8) is important to the processes of repair and remaking. This way, memory becomes more than just a reservoir of experiences, but an actual entity that can be worked upon, manipulated and enacted for fostering a new politics of social repair. Autobiographical accounts of Mi'kmaq poet and residential school survivor Rita Joe are good examples of this. Rita Joe "focuses narrative attention overwhelmingly on positive aspects of her life to the exclusion of fully developed discussions of personal trauma" (McKegney 2007, p. 106). When approached by the Canadian Broadcasting Corporation (CBC) to be involved in a documentary on residential schools, Rita Joe warned that her accounts will only be positive (p. 106). Through her affirmatist literary methodology (p. 107), Rita Joe maintained narrative control over her traumatic experiences and created an honourable image of her life (p. 107, 123). This created conditions conducive to healing (p. 123) and evoked a visible emancipatory politics (p. 106).

On the other hand, King (2011) shows that selective forgetting can be used to dehumanize an entire race. He argues that instead of highlighting the selfless acts of heroism carried out by Black communities in the aftermath of Hurricane Katrina and the Haiti Earthquake, the events have been instead memorialized as encounters of sexual and spiritual (p. 352). King argues that the "process of historical recovery is political work" (p. 356) and must be consciously enacted to dissipate internalized notions of unworthiness and a life unworthy of life (Wynter 2003).

Shaw (2002) explores non-discursive, embodied forms of memory and suggests that there are ways of articulating the past other than through "verbally discursive admissions and projects of public memory" (p. 2). Based on her fieldwork and archival research exploring memories of slave trade in Sierra Leone, Shaw argues that "memories form a prism through which the present is configured even as present experience reconfigures these memories. Memory works both backward and forward" (p. 265). Experiences of disruption and turmoil provoke the "sedimentation of macroprocesses into micropracticies" (p. 6), etching memories of disruption into non-discursive memories that structure the agency of subjects (p. 262). Kleinman and Kleinman (1994) support this assertion:

Bodies transformed by political processes not only represent those processes they experience them as the lived memory of transformed worlds. The experience is of memory processes sedimented in gait, posture, movement, and all the other corporal components which together realize cultural code and social dynamics in everyday practices. The memorialized experience merges subjectivity and social world. (p. 716-717)

Therefore, people do not respond as tabula rasa when they confront disruption (Shaw 2002, p. 10). Shaw's work reveals that embodied and discursive memory helps to dismantle disruption, provide protection and enable a moving on. Her ethnographic research details how slave trade was remembered and turned into creative ritual form. These creative ritual forms are not only forms of remembering but they provide ritual techniques that allow people to live in their present landscapes, e.g. rituals of sealing the house at night for protection are embedded in salve trade memories (p. 102), based on the transformation of spirits who were once neighbours to spirits who are now raiders (p. 50). Such rituals as forms of embodied memories allowed communities to integrate "formerly foreign landscapes into ancestral histories and rituals" and effectively bent and shape current practices to previously existing local schemas (p. 50).

\section{The Agency of Hope}

Freire (1994) links the agency of hope with the possibilities of achieving a meaningful life, he writes "I do not understand human existence, and the struggle needed to improve it, apart from hope and dream. Hope is an ontological need" (p. 2). Hope nurtures the capacity for action and is anchored in practice. Freire asserts "dreaming is not only a necessary political act, it is an integral part of the historico-social manner of being a person. It is part of human nature, which within history, is a permanent process of becoming" (p. 77).

The capacity to hope is not uniformly distributed. Hopelessness is recognized as an outcome of historical, economic and social forces (p. 2). The ability/inability to hope is 
indicative of a subjective reality, of how sense making has been operationalized in an imperfect and non-egalitarian social world. It is a meta-capacity and rich and powerful are better at it. Appadurai (2004) conceives this aspirational capacity as a navigational map allowing marginalized groups to find resources to contest and alter the concrete conditions of their oppression (p. 69). He locates aspirations within "wider, ethical and metaphysical ideas which derive from larger cultural norms", situated in the thick of social life (p. 67). Appadurai writes:

If the map of aspirations (continuing the navigational metaphor) is seen to consist of a dense combination of nodes and pathways, relative poverty means a smaller number of aspirational nodes and a thinner, weaker sense of the pathways from concrete wants to intermediate contexts to general norms and back again. Where these pathways do exist for the poor, they are likely to be more rigid, less supple, and less strategically valuable, not because of any cognitive deficit on the part of the poor but because the capacity to aspire, like any complex cultural capacity, thrives and survives on practice, repetition, exploration, conjecture, and refutation. Where the opportunities for such conjecture and refutation in regard to the future are limited (and this may well be one way to define poverty), it follows that the capacity itself remains relatively less developed. (p. 69)

The capacity to aspire is interlinked with the faculty of voice (Appadurai 2004, p. 70). Appadurai describes voice as a cultural capacity, which must "take some local, cultural form to have resonance, mobilize adherents and capture the public space of debate" (p. 67). The faculty of voice allows the possibility of marginalized groups to mobilize themselves internally (as a group) and "change the dynamics of their consensus in their larger social worlds" (p. 67). This way the formulation of voice nurtures the formation and articulation of collective aspirations.

Any external intervention must therefore be also placed within the aspirational contexts of people (p. 83). The ability to hope implies agency. It is an essential requisite for the process of social remaking, embedded both within the imaginaries of humanization and resuming everyday life. It is also an acquired subjectivity which depending on one's experiences may be developed, nurtured or extinguished and lost.

\section{Everyday Acts of Resistance as Generative Practice}

Everyday actions of resistance, also being a theory of agency, articulate a different scale of politics. The concept became prominent in the 1980s due to a few important theoretical shifts; notably, James Scott's departure from structuralism, Foucault's work on decentered notions of power and the revival of neo-Gramscian notions of hegemony (Bayat 2010, p. 51). The concept of resistance in the everyday is problematic and conceptually inconsistent, but despite its flaws, it has been able to articulate struggle in the space of the local in ways that other theories have been unable to.

The notion of everyday forms of resistance is premised on the idea that most political life of marginalized groups is not found in "overt collective defiance of power holders nor in complete hegemonic compliance, but in the vast territory between these two polar opposites" (Scott 1990, p.136). Scott uses the metaphors of public and hidden transcripts to reveal that the transactions take place between systems of oppression and those it subjugates. These acts of resistance are "firmly anchored in material practices" (p. 188). Thomson (2011) identifies two important qualities of everyday forms of resistance useful to this discussion: (i) they combine persistence, prudence and effort to accomplish a specific goal (such as resuming life after natural disasters); (ii) they provide concrete long-term or temporary benefits to the enactors (e.g. continued access to relief provisions) (p. 446-447).

Everyday resistance operates on a continuum (Thomson 2011, p. 447), there is no standard or pure form and it is largely embedded and unrevealed (Comaroff 1985, p. 261 as quoted in Thomson 2011, p. 447). This means that different actors may employ different forms of resistance depending on their subjective worlds and systems of constraints. The real value is not in deciding which actions constitute non-confrontational resistance and which do not but in capturing the transformations that occur in these transactions. Abu-Lughod (1990) argues that the real value of examining non-collective forms of resistance is the diagnosis it offers of the complex and relational nature of social power in its diverse everyday forms. It makes apparent multiple non-local systems of social power and how they influence community life. It also allows us to develop a nuanced understanding of the heterogeneity of social power without undermining the influence of any one particular form.

The lens of everyday expressions of resistance is simultaneously fine and coarse. It privileges local knowledge and context in interpreting the actions of others without presupposing individual's motivations and behaviours (Thomson 2011, p. 448). Das argues that the concept of resistance is too coarse to capture "the delicate work of selfcreation" (2007, p. 78). The concept has been criticized for reducing the diversity of human struggles to simplistic binaries of oppressed and oppressor and not acknowledging the subaltern's own "forms of inequality and asymmetry" (Ortner 1995 , p. 180). It runs the danger of creating a unitary subject operating within a singular politics (Ortner, p. 175). Focus on everyday resistance even risks depoliticizing the human condition by just drawing attention the politics of resistance at the expense of all other formulations of political life (Ortner, $p$. 176). Similarly, the discourse of domination and resistance has 
a "hegemonic measure to it", in the sense that responses of everyday resistance are "formulated in terms understandable only within the same discourse or political framework" (Finnstrom 2008, p. 186). Real political alternatives remain unarticulated.

Social disruptions such as natural disasters typically take place within existing systems of oppression and exclusion; therefore, the post-disaster space is essentially a space under subjugation. Everyday forms of resistance are distinct from contentious politics, as a tool of social remaking after disruption rather than as a mechanism of analysis of the micropolitics of subversion. These forms of resistance frustrate the system (Thomson 2011, p. 447), enable a "veiled discourse of dignity and self-assertion" (Scott 1990, p. 137) and most importantly make daily life more sustainable (Thomson 2011, p. 447). Such actions "open space for maintaining autonomous everyday social relations and places of encounter" (García 2004 as quoted in Riaño-Alcalá 2012, p. 2; Uribe 2004 as quoted in Riaño-Alcalá 2012, p. 2). They stage rather precariously a "form of politicization (politics) anchored in the decision to survive the war [disruption], to create transitory sites of safety and maintain a relationship with the territory" (Velez 2004 as quoted in Riaño-Alcalá 2012, p. 3). As RiañoAlcalá (2012) asserts that the purpose of everyday acts of resistance is not "exhausted in the mere struggle for economic and physical survival" (p. 8) Rather embedded within these actions are also possibilities towards the reconstruction of spaces and relations that have been destroyed or compromised by social disruption (p. 9). Thus, everyday forms of resistance can carve out generative spaces temporally and materially, which may allow people under domination to continue living and rebuild.

It is this dimension of everyday acts of resistance that makes this concept important for my discussion on social repair and remaking after disruption. For example, as mentioned before, the acts of reopening social spaces such as schools and play grounds in the midst of ongoing violence are strategies of non-direct resistance through which residents restored social spaces to survive, maintain spaces of relationality (Riaño-Alcalá 2012, p. 12) and recreated a sense of normalcy in everyday life (Riaño-Alcalá 2006). These informal social spaces also provide a space for the staging of dissent and political expression (Riaño-Alcalá 2012, p. 121; Scott 1994).

Bayat (2010) forms his point of departure from existing discussions on everyday resistance by arguing that current theorization cannot account for the subjectivities, social space and terrain of political struggles produced by processes of global economic integration (p.43-65). Focusing on the urban poor in Iran, he proposes his own version of everyday resistance which he names "the quiet encroachment of the ordinary" (p. 45). Quiet encroachment refers to "non-collective but prolonged direct actions of dispersed individuals and families to acquire the basic necessities of their lives" in a discreet and unassuming illegal fashion (p. 45). He conceptualizes this form of social renewal as distinct from everyday resistance by maintaining that quiet encroachment seeks to advance new gains and agendas not at the expense of fellow poor or one's self but of the state, powerful and political elite (p.56). These actions are not merely rooted in a politics of protest but of making amends and redress. Actors aim to "expand their space by winning new positions to move on" (p. 56). It extends beyond survival to improvement of life by gaining autonomy and redistribution of goods (p. 59).

Similarly, indigenous struggles of identity politics, reclamation and resurgent knowledge are also rich examples of everyday acts of resistance as generative spaces for social remaking and repair (Corntassel 2012). Adelson (2000) frames the pain of being Abroginal as a particular form of social suffering and defines efforts of cultural and political renewal in everyday life as a direct response to these experiences of suffering. These daily acts of renewal include, for example, increasing reliance on traditional foods, re-speaking cultural languages and reconnecting with the land (Corntassel 2012, p. 89). Acts of regeneration "emanate from recommitments and reorientations at the level of the self that, over time and through proper organization, manifest as broad social and political movements to challenge state agendas and authorities" (Alfred and Corntassel 2005, p. 611). Therefore by resisting cultural imposition by adapting one's own cultural practices, a generative space is enacted which is not only resistant in nature but allows the creation of an alternate political sensibility.

\section{Social Learning in Disruption and Struggle}

The previous sections focussed on some works within popular education literature and ethnographies of political violence to reveal two important, distinct, yet overlapping imaginaries of social repair after disruption. These were the goals of humanization and the incredible task of resumption of daily life. Social repair can be realized by the creative usage of memory, hope and the proclamation of everyday life as a generative space for enacting resistance. This section ties together social repair and remaking with the strategies necessary for its realization via the concept of social learning. Social learning is the naming of the processes by which social repair is realized via the strategic and almost artistic use of memory, hope and resistance.

People in the midst of their precarious lives rely on various social resources embedded within their lifeworlds. This allows them to "achieve a level of complex social coordination that far exceeds our ability to design" (Chamlee-Wright 2010, p.1). After natural disasters, the loss of these social support networks (formal and informal) makes the continuation of life 
extremely difficult. Das (2007) shows that there is a clear gap between the end of violence and resumption of everyday life. In this gap, community reordering strategies such as crafting of new institutions, re-building of networks, linkages and identities are realized.

In her study of community recovery and social learning after Hurricane Katrina, Chamlee-Wright (2010) notes that some communities displayed strong signs of recovery right from the start while others remained in a state of "suspended animation" (p. 2). She was unable to attribute economic status or severity of disaster impact to the ability/inability of a community to show signs of recovery. Chamlee-Wright argues that at the heart of post-disaster recovery is the process of social learning (p.4). Social learning refers to the varied decentralized, bottom-up processes of experimentation, discovery and exchange embedded within specific social, cultural, political contexts which are enacted across the varying spectrums of everyday life, civil society and commercial networks (p. 4). Through a process of "trial, error and discovery individuals and communities learn to creatively deploy the resources within their networks of family, friends, neighbours and religious and professional life to engineer successful strategies for individual recovery" (p. 55). This capacity and ability to deploy socially embedded resources determines the recovery success of a community.

People interpret their environment, take action, learn from their actions and form expectations about what might happen next, and strategize accordingly (Chamlee-Wright 2010, p. 27). As each individual acts, he/she affects the environment of others, redirecting their paths, learnings and expectations (p. 27-28). At any one given time, there are multiple and rival interpretations operational, and each bit of learning changes the very environment to which individuals are responding to (p. 28). There is an "interior life" to people that informs and shapes their actions when faced with difficult circumstances (p. 29). Chamlee-Wright refers to these interpretive or conceptual frames guiding people's actions as mental models.

Using the works of Swidler $(1986,1995,2001)$ and Sewell (1992), Chamlee-Wright (2010) argues that pre-articulate mental models that operate in the background and highly articulated mental models that operate as cultural tools are both essential to understanding human agency (p. 107). Drawing on Swidler (1986, 2001), she states that in unsettled times, such as after natural disasters, communities gain some cognitive distance from their pre-existing cultural contexts (p. 108). In such spaces of disruption, the strategic and creative use of one's culture is more likely as alternate ideas and norms compete for legitimacy. By maintaining a fresh distance from the usual way of doing things, individuals are able to consciously select and deploy certain elements of their cultural worlds in an almost tool-like manner (p. 108). ChamleeWright asserts that by investigating how "pre-articulate mental models get transformed into cultural tools and are combined with other complementary social resources, we understand better how people are able to carve out a sphere of effective agency in an otherwise highly constrained social structure" ( $p$. 105). An example includes the mental templates of independence, hard-work and survival which when consciously articulated in the post-disaster space assumed tool-like properties and inspired people to take initiative instead of waiting for federal assistance (p. 69). These mental templates were in turn influenced by historical experiences of suffering and displacement prior to Hurricane Katrina and made this particular community more resilient than others (p. 69).

Communities strategically locate and employ the socially embedded resources available in their life worlds, proving that ultimately they are the source of resilience and strength in their recovery journeys. Memory as forms of embodiment, emplacement and forgetting; hope and aspirational capacities; and everyday forms of resistance are examples of the various ways these socially embedded resources may be deployed. Subjects employ these resources and others with almost artistic finesse in an effort to re-humanize and resume a sense of normalcy by engaging in everyday life.

\section{Points of Departure from Disaster Recovery Praxis}

Within disaster studies, the conceptual framework of disaster recovery refers to the broad processes by which society is reordered and reconstructed after natural disasters (Haas et al. 1977; Jha et al. 2010). Typically, research on disaster recovery remains focussed on external processes implemented by governments, humanitarian actors and concerned institutions and their interface with communities (e.g. see Berke and Campanella 2006; Olshansky and Chang 2009). Community efforts of re-establishing their lives after natural disasters are conceptualized either as short-term coping strategies or as long-term adaptive mechanisms (e.g. see Alexander 2008; Rajkumar et al. 2008).

Disaster recovery literature remains largely restricted by cyclical approaches to disaster management. First introduced in the 1930s, the cyclical approach to disaster management was popularized by the influential 1979 National Governor's Association report. The report continues to influence the practice of emergency management in the USA (and by default the rest of the world). Phases of the disaster management cycle include disaster preparedness, prevention, relief and recovery. Disaster researchers and practitioners use disaster phases to systematically codify research results and plan interventions (Neal 1997). Conceptual loopholes within the disaster management cycle have been frequently debated, yet the use of this life cycle approach to handling disasters still persists (Neal 1997). According to de Waal, these phases, loaded with "semi-submerged moral values", are mechanisms of management whereby disaster are not, in fact, "prepared 
for, prevented, relieved, or recovered from, but are handled in such a way they pose minimal political threat to governments" (2008, p. ix). Disaster recovery research places inordinate attention on relief agencies and disaster management authorities. We are made to see communities through these institutions as if we are in the seats of control looking downwards. This exaggerates the relative importance of such institutions in the lives of actual human subjects because these institutions are just one of the several actors operating in the peripheries. Communities seem to appear to structure their processes of repair and recovery around institutional responses and this false imagery largely remains uncontested. In fact, institutional-led processes can equally support or hinder local efforts of social repair depending on the thoughtfulness and humility with which they are instituted (Theidon 2006). A social repair orientation to disaster recovery attempts to reverse this imbalance in perception and sees people as people, acting on their own volition, though constrained, but still responding to life as possible.

Restricted by a linear temporal scale which segregates life into before, during and after disasters, the disaster management cycle inadvertently emphasizes the centrality of the disaster event and undermines those experiencing it. Such an abstraction also signals the linear transition of communities from one phase to the other and strongly influences the way disaster response and research is conducted. A social repair orientation to disaster recovery takes a step back from current versions of the disaster management cycle and corresponding research. Since human experiences are not arranged in linear forms and every human portrait only captures a particular moment in time (Erikson 1976, p. 77), a social repair orientation transcends the need to focus on stability, but focuses on the notion of movement, in the intersections of social remaking and disasters as they continuously unfold within community life. In summary, a social repair orientation to disaster recovery differs from existing conceptualizations of disaster recovery in the following ways:

1. A social repair orientation to disaster recovery proposes that a social suffering lens is better suited to capture the complexities of human experiences after natural disasters

Disasters are totalizing phenomenon and they unsettle both material and social domains of life (Oliver-Smith 2005, p. 47). Measurable needs are the prime negotiators of materiality after social disruption legitimizing techno-rational projects of social interventionism (e.g. see Akbari et al. 2004; Akram and Aijazi 2010; Comerio 1997). Less definable, liquid consequences of disasters such as loss of community, erosion of a sense of self, dislocation and despair are also forced physical by equally depoliticizing bio-medical models of trauma, crisis and psycho-social resilience (e.g. see Başoğlu et al. 2004; Carballo et al. 2005; Karanci and Rustemli 1995). Pupavac
(2001, 2004) asserts that trauma (and associated psychosocial models) as rooted within an Anglo-American therapeutic ethos are depoliticizing, jeopardize local coping strategies and reduce politics to mere administration.

Kai Erikson's (1976) account of the destruction of a small rural community in the Appalachian Mountains avoids the "cold parenthesis of theory" (p.13) and delicately captures incommunicable survivor experiences of natural disasters. His work encapsulates the continuous unfolding of disruption in the lives of ordinary people long after the disaster had ceded. Erikson concentrates on what the disaster looked and felt for communities (p. 156). He quotes a survivor describing life after the disaster: "There is something missing, something gone; and that something is very hard to pin down" (p. 195).

Erikson's (1976) account reveals that individuals and communities register their experiences of disruption on various temporal and existential scales. Based on his interviews with survivors, he writes "the worst damage, though, was done to the minds and the spirits of the people who survived the disaster, and it is there that one must begin to search for scars" (p. 135). To explain this point further, Erikson quotes another survivor:

I miss my house and furnishings and clothing, which I have very little of now. I had a large yard, two shade trees. I miss it very much. I miss the pictures from the school year book. A lot of things. It's hard to explain. (p. 198)

On another occasion, Erikson (1976) describes the life of a married couple Deborah and Wilber:

........no neighbours, that's the whole lot of it. Deborah and Wilber had lost a home to which they were attached, lost whatever tone and rhythm kept the family intact, lost a feeling that they were secure in their surroundings, lost the sense, even, that they were fully alive. (p. 146)

These survivor narratives are articulating forms of existential recognition and pain that are very different from the narratives of needs and trauma. Experiences of survival, loss and uncertainty profoundly change individual subjectivities and gives rise to needs which are far more complex than the glib offerings of material reconstruction and therapeutic interventions. Disrupted bodies are multisensory and register the consequences of natural disasters in multiple, and often complementary ways. Yet this full embodiment of the unsettling of natural disasters is interrupted by interventionist discourses which limit human experiences of disruption to sterile, laboratory states. Social interventionism are solidifying projects (Lee 2005, p. 68), they professionalize intimacy (Pupavac 2001, p. 368) and disallow disrupted bodies from articulating their experiences in other expressions, styles and embodiments. Social disruptions such as natural disasters are 
framed in particular ways so that they can be easily intervened upon. Kleinman et al. (1996) support this assertion:

Because of the manner in which knowledge and institutions are organized in the contemporary world as pragmatically-oriented programs of welfare, health, social development, social justice, security and so on, the phenomenon of suffering as an experimental domain of everyday social life has been splintered into measurable attributes. These attributes are then managed by bureaucratic institutions and expert cultures that reify the fragmentation while casting a veil of misrecognition over the domain as a whole. (p. xix)

Bourdieu (1999) draws our attention to social misery, beyond the recognition of material scarcity, as disaster recovery policy tends to emphasize. He affirms "using material poverty as the sole measure of all suffering keeps us from seeing and understanding a whole side of the suffering characteristic of the social order" (p.4). Social suffering results from "what political, economic, and institutional power does to people, and, reciprocally, from how these forms of power themselves influence responses to social problems" (Kleinman et al. 1996, p. xi). As a tool of sense making and understanding the human experience, its strength lies in its ability to defy definition, destabilize established categories and operate in a third space, capturing both the concrete realities of life (such as the need for shelter and food) as well as more existential experiences of survival (Kleinman et al. 1996, 1997). For example, experiences of violence are not solely restricted to the domains of mental health but are also tackled in their political and cultural dimensions (Kleinman et al. 1996, p. xi, 1997, p. ix). Social suffering allows us to understand human experience both under domains of extreme events such as large-scale natural disasters as well as under the "softknife" of everyday oppression and marginality (Kleinman et al. 1996, p. xi).

Attempting to understand human experiences of life under oppression through social suffering collapses old dichotomies, those that separate "individual from social levels of analysis, health from social problems, representation from experience, suffering from intervention" (Kleinman et al. 1996, p. xii). It provides a vocabulary and genre to capture human experiences of disruption as "social forces and cultural phenomenon" bringing to public attention the ways people directly "encounter the social meaning of their afflictions" (Wilkinson 2004, p. 114). As shown by Chuengsatiansup (2001) and Adelson (2001), social suffering can even describe the inter-subjective experiences of communities with relation to collective empowerment and political consciousness.

Human experiences of disasters require a means of articulation that is non-reductionist, sophisticated and embraces complexity. The notion of social suffering may be one such alternative for more appropriately approximating human experiences of disruption. A social suffering lens allows us to capture experiences of natural disasters on a different temporal and dimensional scale, which can shift our conversation away from material reconstruction needs. More importantly, such a shift also enables us to conceptualize disaster recovery on a different evaluative scale, and can help reveal motivations behind the various micro-processes of social recovery enacted by communities and individuals.

2. A social repair orientation to disaster recovery defines disaster survivors as complex beings and as subjects of their own recovery

Human complexity is at odds with the simplified organizational mandates and structures that are designed to help, assist or manage them. This makes social interventions a messy and incomplete project. Whether it is via externally imposed acts of aggression, natural occurrences of disasters or the structural violence of poverty-there are several documented cases where the human endeavour to survive, be political and re-establish community has emerged victorious. Levi's (1989) and Malkki's (1996) accounts of political life of residents in Nazi concentration camps and in Tanzanian refugee camps are some good examples. Institutions responding to social collapse and disruption are typically overwhelmed by the intricacies of social rebuilding and therefore resort to a bizarre over-simplification of the world regardless of how it is lived and experienced. These featureless abstractions, imperfect and impoverished imprints of the world, facilitate the technical, rational discourses of social interventionism. Examples of this include formal transitional justice mechanisms and humanitarian systems, the latter which Agier (2010) describes as totalitarian and fictional (p. 30). Social interventionism is a contested process, overwhelmingly tilted in favour of the status quo and those who formulate it such as nation states and prevailing political (often liberal) logics (Arriaza and Arriaza 2008; Fassin 2012; Thomson 2011).

Freire (1970) argues that it is man's ontological vocation to be a subject who acts upon and transforms his world (1970, p. 37). In this process of re-humanization, qualitatively different spaces are achieved. These new spaces are not necessary oppositional, but cumulatively encroaching through which actors expand their social worlds by winning new territories to move onto (Bayat 2010, p. 56). Chamlee-Wright's (2010) ethnographic research with communities disrupted by Hurricane Katrina reveals the intricate processes of community social learning after disruption. She asserts that individuals possess an inner life which informs and shapes their actions when faced with overwhelming circumstances (p. 28-29). Using the works of Swidler (1986, 2001), Chamlee-Wright demonstrates that in unsettled times, such as after natural 
disasters, communities are able to transform social-embedded resources into "identifiable and deployable cultural tools" (2010, p.108). These skills to resume life are enshrined in the ambition of hope and the navigational capacities of communities (Appadurai 2004; Freire 1994) as well as in the work of memory (Riaño-Alcalá 2006; Shaw 2002) and acts of everyday resistance (Thomson 2011).

3. A social repair orientation to disaster recovery directs attention to the everyday both as a site of knowledge and an articulation of scale for observation

It is important to recognize human experiences of natural disasters which are only partially captured and addressed by existing narratives of needs and materiality. In order to make experiences of disruption more manifest, a social repair orientation to disaster recovery reorients the scale of discussion to that of everyday life.

The everyday is not only an articulation of scale, it is also a revealer of alternate realities. The space of everyday life is a repository of intimate knowledge which makes manifest otherwise hidden forms of impact and recovery. Bayat (2010) explains that the local was salvaged as a significant site of struggle in the climate of decreasing public political action and rise of undemocratic regimes (p. 52). In order to prevent the reduction of subjects as apolitical and lacking agency, it became necessary to acknowledge alternate forms of struggles and politics. The lens of everyday life makes apparent such micro-processes. Freire (1994) argues that the everyday allows the privilege of grounding oneself within the lived realities of subjects and engage in the "knowledge of living experience" (p. 47). He also denies that an attention to the everyday denies the global since after all "the universal emerges from the global" (p. 73).

It is important to recognize that everyday life is much more than a site of intervention or consultation; it is also a space where the "gritty details of biography" can convey the embodied experiences of life during disruption (Farmer 1997, p. 262). The lived space of the everyday, which is basically a refinement of the local, is where social disruption unfolds and also where recovery is enacted. Social disruption "attaches itself with its tentacles into everyday life and folds itself into the recesses of the ordinary" (Das 2007, p. 14) and can strip people of "a sense of everydayness" (Riaño-Alcalá and Baines 2012, p. 387). The everyday is a space carved temporally and materially, which the ruptured body can occupy, inhabit and engage in the vocation of living. Das (2007) recognizes the healing possible by a re-engagement with daily life; she warns "our theoretical impulse is often to think of agency in terms of escaping the ordinary rather than a descent into it. (p. 6-7). Rather, ordinary life reveals the delicate engagement with suffering and healing (Das 2007, p. 15). Das and Kleinman (2001) contend that the mistaken un-eventfulness of the everyday actually accentuates the achievement of resuming life after overwhelming experiences of disruption (p. 1-2).

Similarly, many regions of the world repeatedly experience natural disasters and communities may already have histories of subjugation, dehumanization and exploitation prior to the disaster event. Each new experience of disruption must therefore be studied in relation to the wider web of politics, social subjectivities, life experiences and relationships that reshape life with every new blow. An attention to the everyday helps reveal these persistent structural inequities. This in a way ensures that disaster recovery is not limited to an imagination of mere restoration, where life is returned to as before the disaster event (Mustafa 2003; Wisner and Luce 1993).

Social interventions impact communities at the heart of their existence, in their daily lived realities. The routines of daily life reveal the contestations that take place between external projects of social reconstruction and local aspirations of remaking. The hesitancy of external systems to engage substantially with these lived spaces is reflective of a politics which denigrates local knowledge in a hierarchical system of knowing (Shaw and Waldorf 2010; Theidon 2007). Instead, embodied experiences of social repair and remaking are subjugated to a grand, universal re-ordering ethos regardless of its poor articulation of human experiences.

The everyday is a destabilising force (de Certau 1984) and this becomes apparent as soon as we locate lives as lived within complicated networks of relationships, socioeconomic and political constraints (Riaño-Alcalá and Baines 2012, p. 387). It is also a space of radical meeting, where resistance is enacted, alternative politics are nurtured and historic systems of subjugation are re-engaged.

\section{Implications for Disaster Policy and Practice}

Disaster recovery is considered to be the least studied aspect of a disaster (Berke et al. 1993; Passerini 2000; Weidner 2009). Some even argue that too much emphasis is placed on the disaster event itself instead of the actual recovery process (Garcia-Acosta 2002; McCabe 2002). This had led to an absence of unified theory on disaster recovery rooted in empirical research. Therefore, policy decisions are often made in isolation from actual community realities (Reiss 2012).

A social repair orientation to disaster recovery recognizes people as complex and complete political beings and not just as abstract social categories. This allows us to construct the subject and his/her aspirations of life after disruption as extending beyond mere survival. Das (2007) dispels the notion that such a rich rendering of the human survivor is useless for policy makers who require a reduction of complexity in order to design any form of viable programming. She states that it is only when the meaning of an event is located in the everyday and bears the trace of how shared symbols are worked through 
that programs or policies becomes more effective (p. 217). Finnstrom (2008) reminds us how important it is to complement historical, political and economic meta-narratives with local ethnographies that encompass local understandings of morality, interpretations of history and expectations. Similarly Chamlee-Wright (2010) asserts that if we truly want to understand the ways in which people mobilize culturally embedded resources after natural disasters, "we need to get on the ground and talk to people" (p. 3). Ethnographic engagement also allows us to gauge firsthand whether disaster recovery policy and response is frustrating or supporting local efforts of rebuilding and remaking. A social repair orientation to disaster recovery reveals to policy makers that natural disasters and disaster recovery cannot be isolated from existing socioeconomic conditions, and therefore disaster recovery interventions must seek to dismantle pre-existing structural violence. This includes an intersectional analysis of multiple and intersecting forms of oppression such as race, gender and class that limit survivor abilities to work towards a meaningful life (Crenshaw 1997).

A social repair orientation encourages policy makers to recognize people's capacities to learn in disruption and make conceptual linkages with humanitarian and/or disaster recovery interventions. These processes of learning to deal with disruption are far more profound than their perfunctory capture by the language of coping strategies and adaptation mechanisms. Some programmers have already began understanding the centrality of social learning processes within service provision (e.g. see Muro and Jeffrey 2008; PahlWostl et al. 2007; Pahl-Wostl 2002, 2006) but such discussions remain absent from mainstream disaster recovery praxis.

A process of learning involves changed subjectivities. Vigh (2008) argues that by recognizing crisis as context, new terrains of action and meaning can be explored (p. 8). These spaces may generate and enable stories that express counter narratives and destabilize taken for granted meanings relevant to collective as well as individual subjective experiences. In these spaces, people make sense of the "devastation in the everydayness of life" (Mbembe 1995, p. 331). In her writings on post-conflict Guatemala, Arias (1997) states that it is in the area of subjectivity "that systems of thought develop and knowledge that contributes to the renovation or reconstructing of meaning emerges" (p. 825). An insight into subjective reality is essential for policy makers and programmers because these subjectivities will structure the needs of a community after a crisis and influence their interpretation of the assistance/ programming that is designed for them. It is important that spaces are created which encourage disaster survivors to voice their experiences of resuming life after natural disasters.

Das (2007) argues that while the acknowledgement of human suffering at the state level can undoubtedly foster healing and restore some faith in democratic processes, it is the acknowledgement of suffering at the local level that creates new opportunities for the resumption of everyday life (p. 218). One such example she gives is that of communal spaces for the public mourning of individual and collective loss. Programmers and policy makers can assist in these localized processes of acknowledgement by creating culturally validated social spaces where experiences of loss and dislocation can be negotiated.

Social repair as a response to social suffering faces the danger of dissolving the subject into unrecognizable postmodern fragments with no clear articulation of concrete needs or aspirations. Similar to some of the critiques levied on those operating in the post-development field, it can be argued that by paying inordinate attention to existential dimensions of suffering, conversations on actually changing the terms of resource distribution may be ignored. However, it is important to clarify that a social repair orientation to disaster recovery is not meant to replace existing mandates of service provision after natural disasters. Rather it encourages policy makers and programmers to re-evaluate disaster survivors' relationships with commonly understood needs such as a food, home/shelter, social spaces, etc. as being mediated by a complex set of relationships, memories and familiarity that is essential for returning to a life of meaning. This has direct bearing on the way disaster services are designed.

A social repair orientation to disaster recovery also encourages programmers and policy makers to recreate conditions of everyday life as a starting point for recovery. This means, for example, restoring community playgrounds, places of worship, tea shops and market places. This can also take the form of encouraging culturally validated roles to be part of recovery programming, for example, mothers who may have lost their own children in a disaster are put in charge of providing childcare or assisting in family reunification services as a way for them to regain a form of motherhood. A social repair orientation reflects the long-term nature of disaster recovery. It encourages programmers and policy makers to adopt a longer time frame against which recovery is assessed. It also reveals to policy makers/programmers the intimate nature of disaster recovery necessitating the development of intimate, community-specific and personal recovery indicators.

Acknowledgements The author would like to thank Drs. Shauna Butterwick, Pilar Riaño-Alcalá and Erin Baines for their thoughtful comments on this manuscript.

\section{References}

Abu-Lughod, L. (1990). The romance of resistance: tracing transformations of power through Bedouin women. American Ethnologist, 17(1), 41-55.

Adelson, N. (2000). Re-imagining aboriginality: an indigenous peoples' response to social suffering. Transcultural Psychiatry, 37(1), 11-34. doi:10.1177/136346150003700101. 
Adelson, N. (2001). Reimagining aboriginality: an indigenous people's response to social suffering. In V. Das, A. Kleinman, M. Lock, M. Ramphele, \& P. Reynolds (Eds.), Remaking a world: violence, social suffering, and recovery (pp. 76-101). Berkeley: University of California Press.

Agier, M. (2010). Humanity as an identity and its political effects (a note on camps and humanitarian government). Humanity: An International Journal of Human Rights, Humanitarianism, and Development, 1(1), 29-45.

Akbari, M. E., Farshad, A. A., \& Asadi-Lari, M. (2004). The devastation of Bam: an overview of health issues 1 month after the earthquake. Public Health, 118(6), 403-408. doi:10.1016/j.puhe.2004.05.010.

Akram, S., \& Aijazi, O. (2010). Rapid assessment report offlood-affected communities in Muzaffargarh District, Punjab, Pakistan. Islamabad: Save the Children.

Alexander, S. E. (2008). The resilience of vulnerable households: adjusting to neoliberal capitalism in the aftermath of Hurricane Iris. In N. Gunewardena \& M. Schuller (Eds.), Capitalizing on catastrophe: Neoliberal strategies in disaster reconstruction (pp. 93-116). Plymouth: Altamira Press.

Alfred, T., \& Corntassel, J. (2005). Being indigenous: resurgences against contemporary colonialism. Government and Opposition, 40(4), 597-614.

Appadurai, A. (2004). The capacity to aspire: culture and the terms of recognition. In V. Rao \& M. Walton (Eds.), Culture and public action (pp. 59-94). Stanford: Stanford University Press.

Arias, A. (1997). Comments on consciousness, violence and the politics of memory in Guatemala. Current Anthropology, 38(5), 824-825.

Arriaza, L., \& Arriaza, N. R. (2008). Social reconstruction as a local process. International Journal of Transitional Justice, 2(2), 152-172.

Baines, E., \& Rosenoff-Gauvin, L. (2014). Motherhood and social repair after war and displacement in Northern Uganda. Journal of Refugee Studies. doi:10.1093/jrs/feu001.

Başoğlu, M., Kiliç, C., Salcioğlu, E., \& Livanou, M. (2004). Prevalence of posttraumatic stress disorder and comorbid depression in earthquake survivors in Turkey: an epidemiological study. Journal of Traumatic Stress, 17(2), 133-141. doi:10.1023/B:JOTS. 0000022619.31615.e8.

Bayat, A. (2010). Life as politics. Stanford: Stanford University Press.

Bellah, R. N., Madsen, R., Sullivan, W. M., Swidler, A., \& Tipton, S. M. (1985). Habits of the heart: individualism and commitment in American life. New York: Harper and Row. Quoted in OliverSmith, A. (2010). Defying displacement: grassroots resistance and the critique of development. Austin: University of Texas Press.

Berke, P., \& Campanella, T. (2006). Planning for post-disaster resiliency. The Annals of the American Academy of Political and Social Science, 604, 192-207.

Berke, P. R., Kartez, J., \& Wenger, D. (1993). Recovery after disaster: achieving sustainable development, mitigation and equity. Disasters, 17(2), 93-109.

Bourdieu, P. (1999). The weight of the world: social suffering in contemporary society. Cambridge: Polity.

Carballo, M., Heal, B., \& Hernandez, M. (2005). Psychosocial aspects of the tsunami. Journal of the Royal Society of Medicine, 98(9), 396399.

Chamlee-Wright, E. (2010). The cultural and political economy of recovery: social learning in a post-disaster environment. New York: Taylor \& Francis.

Chaudhry, L. N. (2004). Reconstituting selves in the Karachi conflict: Mohajir women survivors and structural violence. Cultural Dynamics, 16(2-3), 259-290.

Chuengsatiansup, K. (2001). Marginality, suffering and community: the politics of collective experience and empowerment in Thailand. In V. Das, A. Kleinman, M. Lock, M. Ramphele, \& P. Reynolds (Eds.), Remaking a world: violence, social suffering, and recovery (pp. 3175). Berkeley: University of California Press.
Comaroff, J. (1985). Body of power, spirit of resistance: the culture and history of a South African people. Chicago: University of Chicago Press. Quoted in Thomson, S. (2011). Whispering truth to power: the everyday resistance of Rwandan peasants to post-genocide reconciliation. African Affairs, 110(440), 439-456.

Comerio, M. C. (1997). Housing issues after disasters. Journal of Contingencies and Crisis Management, 5(3), 166-178.

Corntassel, J. (2012). Re-envisioning resurgence: indigenous pathways to decolonization and sustainable self-determination. Decolonization: Indigeneity, Education, Society, 1(1), 86-101.

Crenshaw, K. (1997). Mapping the margins: intersectionality, identity politics, and violence against women of color. In K. J. Maschke (Ed.), The legal response to violence against women (pp. 91-150). New York: Garland Publishing.

Das, V. (2007). Life and worlds: violence and the descent into the ordinary. Berkeley: University of California Press.

Das, V., \& Kleinman, A. (2001). Introduction. In V. Das, A. Kleinman, M. Lock, M. Ramphele, \& P. Reynolds (Eds.), Remaking a world: violence, social suffering, and recovery (pp. 1-30). Berkeley: University of California Press.

de Alwis, M. (2004). The 'purity' of displacement and the reterritorialization of longing: Muslim women refugees in northwestern Sri Lanka. In W. Giles \& J. Hyndman (Eds.), Sites of violence: feminist politics in conflict zones (pp. 213-231). Berkeley: University of California Press.

de Certau, M. (1984). The practice of everyday life. Berkeley: University of California Press.

de Waal, A. (2008). Foreword. In N. Gunewardena \& M. Schuller (Eds.), Capitalizing on catastrophe: Neoliberal strategies in disaster reconstruction (pp. ix-xiv). Plymouth: Altamira Press.

Donnan, H., \& Simpson, K. (2007). Silence and violence among Northern Ireland border Protestants. Ethnos, 72(1), 5-28.

Erikson, K. (1976). Everything in its path: destruction of community in the Buffalo Creek Flood. New York: Simon and Schuster.

Farmer, P. (1997). On suffering and structural violence: a view from below. In A. Kleinman, V. Das, \& M. Lock (Eds.), Social suffering (pp. 261-284). Berkeley: University of California Press.

Fassin, D. (2012). Humanitarian reason: a moral history of the present. Berkeley: University of California Press.

Finnstrom, S. (2008). Living with bad surroundings: war, history, and everyday moments in northern Uganda. Durham: Duke University Press.

Fletcher, L. E., \& Weinstein, H. M. (2002). Violence and social repair: rethinking the contribution of justice to reconciliation. Human Rights Quarterly, 24(3), 573-639.

Freire, P. (1970). Pedagogy of the oppressed. New York: Continuum.

Freire, P. (1994). Pedagogy of hope: reliving pedagogy of the oppressed. London: Continuum.

García, C. I. (2004). Resistencias. Análisis comparado de la acción colectiva frente a la guerra en urabá y oriente antioqueno. Nómadas, 20, 102-110. Quoted in Riaño-Alcalá, P. (2012). "Quitar espacio a la guerra": Mapping everyday responses to violence in contexts of armed violence. In Surviving violence: Comparative perspectives (pp. 1-14). Halifax (Conference Proceeding).

Garcia-Acosta, V. (2002). Historical disaster research. In A. Oliver-Smith \& S. M. Hoffman (Eds.), Catastrophe \& culture (pp. 49-66). Santa Fe: School of American Research Press.

Haas, J. E., Kates, R. W., \& Bowden, M. J. (1977). Reconstruction following disaster. Massachusetts: MIT Press.

Jha, A.K., Barenstein, J.D., Phelps, P.M., Pittet, D., \& Sena, S. (2010). Safer homes, stronger communities: a handbook for reconstructing after natural disasters. Washington, DC: World Bank Publications. 
Karanci, A. N., \& Rustemli, A. (1995). Psychological consequences of the 1992 Erzincan (Turkey) earthquake. Disasters, 19(1), 8-18. Retrieved from http://www.ncbi.nlm.nih.gov/pubmed/7735861.

King, J. (2011). Who dat say (we) "Too depraved to be saved"?: remembering Katrina/Haiti (and beyond): critical studyin' for human freedom. Harvard Educational Review, 81(2), 343-371.

Kleinman, A., \& Kleinman, J. (1994). How bodies remember: social memory and bodily experience of criticism, resistance and deligitimation following China's cultural revolution. New Literary History, 25, 708-723.

Kleinman, A., Das, V., \& Lock, M. (1996). Introduction. Daedalus, 125(1), xi-xx.

Kleinman, A., Das, V., \& Lock, M. (1997). Introduction. In A. Kleinman, V. Das, \& M. Lock (Eds.), Social suffering (pp. ix-xxv). Berkeley: University of California Press.

Lee, R. L. M. (2005). Bauman, liquid modernity and dilemmas of development. Thesis Eleven, 83(1), 61-77.

Levi, P. (1989). The drowned and the saved. New York: Vintage Books.

Malkki, L. H. (1996). Speechless emissaries: refugees, humanitarianism, and dehistoricization. Cultural Anthropology, 11(3), 377-404.

Mbembe, A. (1995). Figures of the subject in times of crisis. Public Culture, 7(2), 323-352.

McCabe, J. T. (2002). Impact of and response to drought among Turkana pastoralists. In A. Oliver-Smith \& S. M. Hoffman (Eds.), Catastrophe \& culture (pp. 213-236). Santa Fe: School of American Research Press.

McKegney, S. (2007). Magic weapons: Aboriginal writers remaking community after residential school. Winnipeg: University of Manitoba Press.

Mehta, D., \& Chatterji, R. (2001). Boundaries, names, Arteritis. In V. Das, A. Kleinman, M. Lock, M. Ramphele, \& P. Reynolds (Eds.), Remaking a world: violence, social suffering, and recovery (pp. 201-249). Berkeley: University of California Press.

Muro, M., \& Jeffrey, P. (2008). A critical review of the theory and application of social learning in participatory natural resource management processes. Journal of Environmental Planning and Management, 51(3), 325-344.

Mustafa, D. (2003). Reinforcing vulnerability? Disaster relief, recovery, and response to the 2001 flood in Rawalpindi, Pakistan. Global Environmental Change Part B: Environmental Hazards, 5(3-4), $71-82$.

National Governor's Association. (1979). Emergency preparedness project final report. Washington D.C: Government's Printing Office.

Neal, D. M. (1997). Reconsidering the phases of disaster. International Journal of Mass Emergencies and Disasters, 15(2), 239-264.

Oliver-Smith, A. (2005). Communities after catastrophe: reconstructing the material, reconstituting the social. In S. E. Hyland (Ed.), Community building in the twenty-first century (pp. 45-70). Santa Fe: School of American Research Press.

Oliver-Smith, A. (2010). Defying displacement: grassroots resistance and the critique of development. Austin: University of Texas Press.

Olshansky, R., \& Chang, S. (2009). Planning for disaster recovery: emerging research needs and challenges. Journal of Progress in Planning, 72, 200-209.

Ortner, S. B. (1995). Resistance and the problem of ethnographic refusal. Comparative Studies in Society and History, 37(1), 173-193.

Pahl-Wostl, C. (2002). Towards sustainability in the water sector-the importance of human actors and processes of social learning. Aquatic Sciences, 64(4), 394-411.

Pahl-Wostl, C. (2006). The importance of social learning in restoring the multifunctionality of rivers and floodplains. Ecology and Society, 11(1), 10.

Pahl-Wostl, C., Craps, M., Dewulf, A., Mostert, E., Tabara, D., \& Taillieu, T. (2007). Social learning and water resources management. Ecology \& Society, 12(2), 1-19.

Passerini, E. (2000). Disasters as agents of social change in recovery and reconstruction. Natural Hazards Review, 1(2), 67-72.
Pupavac, V. (2001). Therapeutic governance: psycho-social intervention and trauma risk management. Disasters, 25(4), 358-372.

Pupavac, V. (2004). Psychosocial interventions and the demoralization of Humanitarianism. Journal of Biosocial Science, 36(4), 491-504.

Rajkumar, A. P., Premkumar, T. S., \& Tharyan, P. (2008). Coping with the Asian tsunami: perspectives from Tamil Nadu, India on the determinants of resilience in the face of adversity. Social Science \& Medicine, 67(5), 844-853.

Reiss, C. L. (2012). Introduction to the special issue on disaster recovery. International Journal of Mass Emergencies and Disasters, 30(2), $120-122$.

Riaño-Alcalá, P. (2006). Dwellers of memory. Youth and violence in Medellin Columbia. New Jersey: Transaction Publishers.

Riaño-Alcalá, P. (2012). "Quitar espacio a la guerra": mapping everyday responses to violence in contexts of armed violence. In Surviving violence: comparative perspectives (pp. 1-14). Halifax (Conference Proceeding).

Riaño-Alcalá, P., \& Baines, E. (2012). Editorial note. International Journal of Transitional Justice, 6(3), 385-393. doi:10.1093/ijtj/ijs027.

Rosenoff-Gauvin, L. (2013). In and out of culture: Okot p'Bitek's work and social repair in post-conflict Acoliland. Oral Tradition, 28(1), $35-54$.

Scott, J. C. (1990). Domination and the arts of resistance: hidden transcripts. New Haven: Yale University Press.

Sewell, W. (1992). A theory of structure: duality, agency, and transformation. American Journal of Sociology, 98(1), 1-29.

Shaw, R. (2002). Memories of the slave trade: ritual and the historical imagination in Sierra Leone. Chicago: University of Chicago Press.

Shaw, R., \& Waldorf, L. (2010). Introduction. In R. Shaw, L. Waldorf, \& P. Hazan (Eds.), Localizing transitional justice: interventions and priorities after mass violence (p. 2). Stanford: Stanford University Press.

Swidler, A. (1986). Culture in action: symbols and strategies. American Sociological Review, 51, 273-286.

Swidler, A. (1995). Culture, power and social movements. In H. Johnston \& B. Klandermans (Eds.), Social movements and culture (pp. 25 40). Minneapolis: University of Minnesota Press.

Swidler, A. (2001). Talk of love: how culture matters. Chicago: University of Chicago Press.

Theidon, K. (2006). Justice in transition: the micropolitics of reconciliation in postwar Peru. Journal of Conflict Resolution, 50(3), 433457. doi:10.1177/0022002706286954.

Theidon, K. (2007). Transitional subjects: the disarmament, demobilization and reintegration of former combatants in Colombia. International Journal of Transitional Justice, 1(2), 66-90.

Thomson, S. (2011). Whispering truth to power: the everyday resistance of Rwandan peasants to post-genocide reconciliation. African Affairs, 110(440), 439-456.

Uribe, M. T. (2004). Emancipación social en un contexto de guerra prolongada. El caso de la comunidad de paz de San José de apartado. In B. De Souza \& M. Garcia (Eds.), Emancipación social y violencia en Colombia (pp. 75-117). Bagota: Norma. Quoted in RiañoAlcalá, P. (2012). "Quitar espacio a la guerra”: Mapping everyday responses to violence in contexts of armed violence. In Surviving violence: comparative perspectives (pp. 1-14). Halifax (Conference Proceeding).

Velez, J. C. (2004). Prácticas hegemónicas y resistencias cotidianas. Una perspectiva para estudiar la formación del Estado en Colombia. Estudios Políticos, 25, 89-111. Quoted in Riaño-Alcalá, P. (2012). "Quitar espacio a la guerra": Mapping everyday responses to violence in contexts of armed violence. In Surviving Violence: Comparative Perspectives (pp. 1-14). Halifax (Conference Proceeding). 
Vigh, H. (2008). Crisis and chronicity: anthropological perspectives on continuous conflict and decline. Ethnos, 73(1), 5-24.

Weidner, J. S. (2009). Review of disaster recovery. Journal of Homeland Security and Emergency Management, 6(1), 1-2.

Wilkinson, I. (2004). The problem of "social suffering": the challenge to social science. Health Sociology Review, 13(2), 113-121.
Wisner, B., \& Luce, H. R. (1993). Disaster vulnerability: scale, power and daily life. GeoJournal, 30(2), 127-140.

Wynter, S. (2003). Unsettling the coloniality of being/power/ truth/freedom: towards the human, after man, its overrepresentation-an argument. New Centennial Review, 3(3), 257337. 